\title{
Implementation of the Nursing Services Management Model in 16 hospitals
}

\author{
Implantação do Modelo de Gestão de Serviços de Enfermagem em 16 hospitais \\ Implementación del Modelo de Gestión de Servicios de Enfermería en 16 hospitales
}

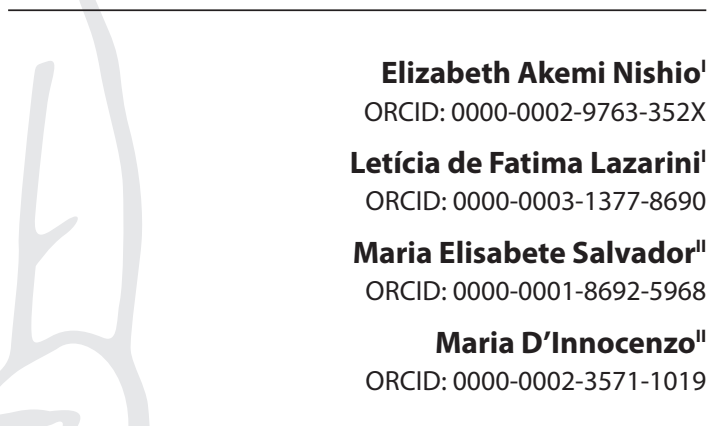

'Associação Paulista para o Desenvolvimento da Medicina. São Paulo, São Paulo, Brazil. "Universidade Federal de São Paulo. São Paulo, São Paulo, Brazil.

How to cite this article: Nishio EA, Lazarini LF, Salvador ME, D'Innocenzo M. Implementation of the Nursing Services Management Model

in 16 hospitals. Rev Bras Enferm. 2021;74(1):e20190756. doi: http://dx.doi.org/10.1590/0034-7167-2019-0756

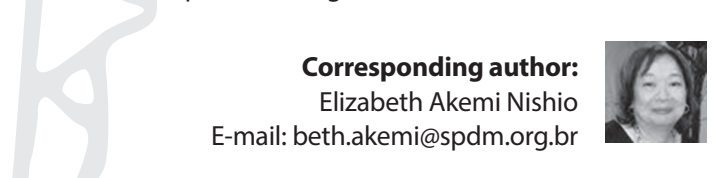

EDITOR IN CHIEF: Dulce Barbosa ASSOCIATE EDITOR: Andrea Bernardes

Submission: $10-24-2019$

Approval: 08-03-2020

\begin{abstract}
Objectives: to describe the main aspects and relevant results of the implementation of the Nursing Services Management Model in hospitals managed by social health organization, from 1998 to 2018. Methods: experience report of the model implemented in 16 hospitals in the state of São Paulo, Brazil. Results: the actions and monitoring of the implementation were based on protocols considering: management model and structure of the nursing service in hospitals; care process and main nursing care results; and people development. Final Considerations: the implementation of methods that ensure the well-being of nursing professionals is directly related to effective care, in which the practice is driven by quality and autonomy. Promoting a culture of care excellence, at different levels of management and care, has generated better expectations and motivation. It was found that the commitment of managers, by providing resources, resulted in improvements in the quality of nursing services. Descriptors: Models, Organizational; Hospital Administration; Health Management; Delivery of Health Care; Nursing.
\end{abstract}

\section{RESUMO}

Objetivos: descrever os principais aspectos e resultados relevantes da implantação do Modelo de Gestão de Serviços de Enfermagem em hospitais gerenciados por uma organização social de saúde, de 1998 a 2018. Métodos: relato de experiência do modelo implantado em 16 hospitais no estado de São Paulo, Brasil. Resultados: as ações e monitoramento da implantação basearam-se em protocolos considerando-se: modelo de gestão e estrutura do serviço de enfermagem dos hospitais; processo assistencial e principais resultados da assistência de enfermagem; e desenvolvimento de pessoas. Considerações Finais: a implantação de métodos que garantam o bemestar dos profissionais de enfermagem está diretamente relacionada ao cuidado eficaz, em que a prática é movida pela qualidade e autonomia. Promover cultura de excelência assistencial, em diferentes níveis da gestão e do cuidado, gerou melhores expectativas e motivação. Verificou-se que o comprometimento dos gestores, ao prover recursos, resultou em melhorias na qualidade dos serviços de enfermagem. Descritores: Modelos Organizacionais; Administração Hospitalar; Gestão em Saúde; Assistência à Saúde; Enfermagem.

\section{RESUMEN}

Objetivos: describir los aspectos principales y los resultados relevantes de la implantación del Modelo de Administración de Servicios de Enfermería en hospitales administrados por una organización social de salud, de 1998 a 2018. Métodos: informe de experiencia del modelo implantado en 16 hospitales del estado de Sao Paulo, Brasil. Resultados: las acciones y el monitoreo de la implantación se basaron en protocolos considerándose: modelo de administración y estructura del servicio de enfermería de hospitales; proceso asistencial y resultados principales de la asistencia de enfermería; y desarrollo de personas. Consideraciones Finales: la implantación de métodos que garantizan el bienestar de profesionales de enfermería está directamente relacionada al cuidado eficaz, donde la práctica es movida por la calidad y la autonomía. Promover una cultura de excelencia asistencial, en diferentes niveles de gestión y atención, generó mejores expectativas y motivación. Se verificó que el compromiso de los encargados, al proporcionar recursos, resultó en mejoras en la calidad de los servicios de enfermería.

Descriptores: Modelos Organizacionales; Administración Hospitalaria; Administración en Salud; Asistencia a la Salud; Enfermería. 


\section{INTRODUCTION}

In the hospital area, nursing has been facing challenges and demands that expose adaptation needs on the part of leaders and managers in the creation of different forms of management and in the search for work processes that promote a critical eye ${ }^{(1)}$. Such professionals are taking on executive positions that have become an essential part of organizations; and, after many advances, the perspective of patient care is strategically located at the executive level of the new structures ${ }^{(1)}$.

In this scenario, health councils and hospital leaders from the international community warn of the awareness of risks and responsibilities in assuming attitudinal changes in management leadership that clearly impact the quality and safety of work ${ }^{(2)}$. Studies recommend and request hospital managers to take responsibility for management results and quality care ${ }^{(2-3)}$. Setting priorities and disseminating strategic goals is directly related to high hospital performance, the core of hospital management ${ }^{(3)}$.

Actions and efforts have been observed in scientific evidence. Today, however, it is necessary to investigate and evaluate different aspects of management, such as: the difficulties faced by managers; the results of leaders on quality improvement; practices and engagement to ensure effective care; time spent reviewing management models; frequent use of sources and guidelines of studies based on evidence and methodologies available for decision making; areas and organizational structures that deserve more attention; among other elements relevant to the performance of these professionals ${ }^{(2-3)}$.

In fact, leadership skills are key, as are interpersonal skills. Nurse managers must qualify and create ways to lead and manage, where different resources are able to move between the clinical and operational domains, transforming performance demands into operational strategies and tactics ${ }^{(4)}$.

The evaluation of the quality of care refers to Donabedian ${ }^{(5)}$, precursor to the evaluation of the quality of health institutions, considering the constructions of the structure, processes and results. The relationships between the constructs (structure, processes and results) are based on the idea that an adequate structure with paths or guidelines should promote satisfactory processes and results.

The concept of nursing care management, in a hospital setting, involves a relationship of dialogue between know-how/management and know-how/care. Nursing leadership uses administrative tools for the management method in order to plan, execute, evaluate and control. The means, in turn, are managerial instruments that act in the coordination, supervision, communication, observation and delegation of the processes for the realization of nursing practices in an organized manner, with a systematized team, in search of the best results ${ }^{(6)}$. Hospitals that conduct performance monitoring obtain significantly higher scores in the care process and lower rates of adverse events than services that do not $^{(3)}$. It is clear, therefore, that nursing managers should be in a privileged position to recommend models, structures, procedures, policies and work the organizational climate of the institutions. This professional acts with priorities, and his role is expressive and obvious in the search for quality of care, safety to patients and employees.

From this perspective, leaders and nursing managers of the Organização Social de Saúde (OSS) Associação Paulista para o
Desenvolvimento da Medicina (SPDM Affiliates) analyzed and identified substantial improvements in hospitals incorporated into the management of this institution. Promoting and guaranteeing individualized and safe care for the patient through the nursing care process - Nursing Care Systematization (NCS), among other advances, were priorities for the implementation of a new model of nursing care management, under the light of responsible and coherent administrative tools.

With support and encouragement from the nursing team, directors and superintendent of OSS-SPDM Affiliates, the Nursing Services Management Model (NSMM) was implemented in 16 hospitals managed by the aforementioned institution. Thus, motivated by the promising results of a long working process, the authors of the present study considered it relevant to describe the challenges and valuable experiences that permeated two decades of studies, analyses and reflections on the implementation of a management model for the nursing services of public hospitals.

\section{OBJECTIVES}

To describe the main aspects and most relevant results of the implementation and monitoring of the Nursing Services Management Model in 16 hospitals managed by OSS-SPDM Affiliates, in the period of 20 years of activity (1998-2018).

\section{METHODS}

It is a descriptive experience report type study on the main aspects of the implementation process of the Nursing Services Management Model in 16 public hospitals, with 3.601 beds and 7.500 nursing professionals. This process, which integrated theoretical and practical knowledge in the solidification of a work methodology, is described in this study in four axes: 1. Management Model of Hospital Nursing Services; 2 . Structure of NSMM Nursing Service in hospitals managed by OSS-SPDM Affiliates; 3. Nursing Care Process and main results of Nursing Care; 4. Development of People.

When contextualizing the scenario of nursing performance in hospitals managed by Social Health Organization, it is important to highlight that the OSS-SPDM Affiliates manages health institutions in two national states with state public partnerships. Establishing techniques and working methods was necessary to develop and conduct standardized training and supervision of leaders, whose standard of management and care comes from services validated over 20 years of experience. In this scenario, the challenge of managing newly-incorporated hospitals with OSS-SPDM Affiliates management, in which the transition between the adopted model and the new work processes involves multi-professional and multidisciplinary actions of fundamental importance for professionals, patients and the community as a whole, is highlighted.

\section{EXPERIENCE REPORT}

\section{Hospital Nursing Services Management Model}

Implemented in 16 hospitals managed by OSS-SPDM Affiliates, NSMM is coordinated by professionals from the Corporate 
Nursing Center (CNC). It is important to note that nursing services do not operate in a solitary manner; NSMM is part of the institution's model of care with other professionals who are part of the hospital care, namely: clinicians, physiotherapists, psychologists, speech therapists, social worker, occupational therapist and others.

The CNC is subordinated to the Superintendence of OSS-SPDM Affiliates. In order to coordinate, guide and monitor the performance of the Nursing Services of the institutions managed by the aforementioned OSS, the nucleus also promotes actions to seek excellence in health care quality. It excels in patient safety, risk management and continuous improvement of the team, based on the guidelines of the institution. Thus, the activities of CNC contemplate the nursing care project of the "new" hospital from the implementation and monitoring of institutional performance.

The NSMM protocol presents a program of implantation in a newly assumed institution and has four axes: 1 . Implantation of the structure of the Nursing Service (SE); 2 . Implantation of the Nursing Care Process; 3. Development of People; 4 . Results of the nursing care. The program also has a schedule of actions for these institutions that provides, in the first two years of implementation, training activities and ongoing training of the team.

In order to monitor NSMM follow-up and align actions with the results of nursing services, CNC professionals organize monthly meetings with nursing directors and coordinators, as well as periodic meetings with Continuing Education supervisors of institutions.

\section{Structure of NSMM Nursing Services in hospitals managed by OSS-SPDM Affiliates}

The structure of the NSs is described in the internal regulations, which include guidelines, policy, philosophy and objectives of institutional nursing. It contemplates the Nursing Board organizational chart, nursing dimensioning, forms of selection and contracting, as well as the general and specific procedure manuals adopted in the institutions. The responsibilities of the nursing team are organized as follows: Nursing Technicians and Assistants: they perform the nursing procedures. Nurse: is responsible for the care management and Care Unit. Clinical Nurse: acts in the care line. Nursing Supervisor: is responsible for the management of the nursing and maintenance body of NSMM. Continuing Education Supervisor: ensures NSMM for training and qualification of nursing staff. Nursing Manager: responsible for the nursing care result and multidisciplinary relationship acting in this interface. Nursing Director: acts at the strategic level in the institutional care model with other medical directors, administrative and superintendence.

There are differences in each institution, however the basic structure of nursing service is maintained by preserving the characteristics proper to each institution - for example, sizing of the nursing team. It should be noted that the subrogation of professionals working in hospitals recently incorporated by the management OSS-SPDM Affiliates are submitted to the process of adaptation and training for the new model of care.

\section{NSMM Care Process and main nursing care results}

Since the beginning of the management activities of OSS-SPDM Affiliates in 1998, the concern has been to ensure individualized care and actions aimed at patient safety through the NCS, executed in a partial manner. The priority, therefore, was to survey problems and prescribe care for all patients in hospitals and outpatients. It is noteworthy that the NCS is based on Wanda Horta's Basic Human Needs Theory, Dorothea Orem's Self-Care Theory and Florence's Environment Theory ${ }^{(7)}$. It contemplates the risks of the patient identified during the history, physical examination and procedures performed by the nurse, as well as the prescribed barriers, such as prevention of preventable events related to care or nursing sensitivity.

In 1999, quality management was initiated by adopting individualized NCS for all patients with all stages (description of the care and support processes). For this, it was necessary to establish internal agreements between the Care Units and the Administrative Units. For example, the supply of hospital clothing should occur three times a day with a volume defined per Care Unit; prescribed medication - the Pharmacy should deliver to the Care Units a unitized kit (process of packaging and identifying medication) with medication and supplies. Thus, the objective is to ensure that operational professionals are in a satisfactory position to provide quality care.

In 2000, the management of safety risks to the assisted patient began. The first preventive action was to prepare the drug therapy protocol by the nursing and pharmacy teams. In 2001, the pharmacy was responsible for preparing the most commonly used medicines in the hospital (injectable and oral); and nursing, for administering. A series of labels with identification of the pharmacist who prepares the drug was implemented, with a check made by the nursing professional who administers it.

In 2002, special care was adopted for the management of and access to 13 drugs considered "high alert". Thus, the pharmacy dispenses such medication with yellow label, and the administration should be performed by double checking (two nursing professionals check the medication, dose, route of administration, right patient). Other actions to prevent adverse events include prescriptions from nurses: e.g., Pressure Ulcer (PU), phlebitis, falls, and risks of care-related nosocomial infections.

In 2004, six international safety targets recommended by the World Health Organization (WHO) were implemented ${ }^{(8)}$ to reduce risks and mitigate adverse events: 1 . patient identification; 2 . effective team communication; 3 . safety of high surveillance drugs; 4. surgical intervention (correct site, correct patient); 5 . Hand washing; 6 . Reduction of the risk of injuries due to falls and PU.

Since 2007, the Marie Manthey model, author of the Primary Nursing theory ${ }^{(9)}$, has been used in the management of wards and care lines. The nurse is a reference for the patients or group and is responsible for drawing up 24-hour care plans. In that same year, clinical care nurses, with full autonomy, were admitted to administer the management of care to patients. They organize the nursing work and study the patients' evolution information helping the multi-professional team and the patients' relatives.

In compliance with the recommendations of the Humanization Program of the Unified Health System and, patient safety in the emergency room and emergency room (open-door hospitals), in 2014, a Reception with Risk Classification was implemented in order to prioritize medical care. It was found that, after medical care, there was no management of patient follow-up regarding 
procedures and definition of the medical outcome, resulting in waiting of 6 to 12 hours. Thus, reference teams were introduced, consisting of a nurse and two to three nursing technicians. This team attends and manages patients from medical care, in the performance of procedures such as medication and complementary exams, until the clinical outcome, in no more than four hours.

According to records and reports from the institutions' databases, an improvement in patient and family satisfaction was identified from $68 \%$ to $87 \%$. Among patients and family members' statements, the following reports stand out: "closer professionals"; "valorization in quick care".

As a management tool for the Care Unit, daily management was adopted, a method adapted from the Lean Model ${ }^{(10)}$, with active participation of nurses in order to expedite and monitor the patient's treatment including, in particular, monitoring the length of stay in the unit, according to the schedule made at admission. The method consists of extended multi-professional and daily visits by nurses, clinicians, surgeons, physiotherapists, social workers, pharmacists and nutritionists.

Other tools used by the multidisciplinary team include the Patient Centered Care Plan and the Palliative Care Program which have expressive nursing participation in all stages. The results observed have been encouraging, such as a reduction in the length of hospitalization, a reduction in the delay or suspension of tests and treatment. According to data from institutional reports performed periodically and validated by the OSS SPDM Affiliates superintendence, there was a reduction in the suspension of exams and surgeries from $15 \%$ to $5 \%$.

The post-discharge guidance showed efficacy in patients, whose impression, verified in the outpatient return, showed better knowledge of self-care, observed even by tests and clinical status. Another relevant fact was the reduction of hospital infection from 5.5\% in 2007 to $4.88 \%$ in 2015; 2.72\% in 2016 to $2.9 \%$ in 2017 . As for the Palliative Care Program, there was a reduction in the average stay of chronic patients from 200 to 50 days, from the implementation of the care related to the techniques of that program, according to records in the OSS-SPDM Affiliated Databases.

In relation to the evaluation of users on nursing care, consolidated data from the User Care Service are verified in 12 hospitals. It was seen that, between 2013 and 2017, eight institutions increased from $81 \%$ to $98 \%$, approximately.

\section{People Development}

In relation to the philosophy of "caring for those who care", the nursing managers of OSS-SPDM Affiliates have promoted teamwork in order to support nursing professionals through the Mindfulness technique, whose research was conducted by nurses and psychiatric doctors, specialists in health environments of the institution itself. In addition, different initiatives were introduced, such as: development of full attention and comfort to professionals; use of sensitive and individualized listening techniques, especially in the face of team conflicts; training and preparation of leaders for conflict resolution; non-violent communication; among other actions.

In line with these initiatives, we highlight the national and international certifications achieved by the institutions managed by OSS-SPDM Affiliates: of the 16 hospitals, one obtained Level I Hospital Accreditation Certification; and another at Level II Full Certification; four hospitals with Level III Certification of Excellence; and two with QMentum International of the Canadian Accreditation Program.

\section{FINAL CONSIDERATIONS}

Over 20 years in the management of public hospitals, leaders and nurse managers have spared no effort to organize, analyze and implement work processes focused on strategies, data and organizational culture. Identifying priorities, aligned with quality and safety goals, were management actions executed at timely moments, creating a strategic planning agenda that considers the active roles of professionals for decision making.

It is understood that genuine nursing service work processes favor a suitable working environment. The promotion of tools, methods and techniques that ensure the welfare of professionals is directly related to effective care, where professional practice is driven by quality and autonomy, in order to meet the expectations and demands of society.

In fact, the cultivation of care excellence at different levels of management and care, articulating the organizational culture with professional teams, has generated better expectations, engagement and motivation. Likewise, it was possible to verify that the commitment of managers in providing resources, ensuring high quality standards and the responsibility of the managerial role can result in a significant impact on the quality of services.

\section{REFERENCES}

1. Leggat SG, Balding C. Bridging existing governance gaps: five evidence-based actions that boards can take to pursue high quality care. Aust Health Rev. 2019;43(2):126-32. doi: 10.1071/AH17042

2. Hughes H, Churchill N. Speaking up in the NHS in England: the work of the National Guardian and NHS England. Br J Gen Pract. 2017;67 (658):198-9. doi: 10.3399/bjgp17X690581

3. Brown A. Understanding corporate governance of healthcare quality: a comparative case study of eight Australian public hospitals. BMC Health Serv Res. 2019; 19(1):725. doi: 10.1186/s12913-0194593-0

4. Ducharme MP, Bernhardt JM, Padula CA, Adams JM. Leader Influence, the Professional Practice Environment, and Nurse Engagement in Essential Nursing Practice. J Nurs Adm. 2017;47(7-8):367- 75. doi: 10.1097/NNA.0000000000000497

5. Donabedian A. Continuity and change in the quest for quality. Clinical Performance and Quality in Health Care. New York: 1993;1(1):9-16 p. 
6. Liang Z, Howard PF, Leggat S, Bartram T. Development and validation of health service management competencies. J Health Organ Manag. 2018;32(2):157-75. doi: 10.1108/JHOM-06-2017-0120

7. George JB. Teoria de Enfermagem Os fundamentos para a prática profissional. Tradução Regina Machado Garces. $4^{a}$ ed. Porto Alegre: Artes Médicas, 1993. 338 p.

8. Brasil, Ministério da Saúde, Fundação Oswaldo Cruz, ANVISA. Documento de referência para o Programa Nacional de Segurança do Paciente[Internet]. Brasília. 2014 [cited 2019 Dec 30]. Available from: http://bvsms.saude.gov.br/bvs/publicacoes/documento_referencia_ programa_nacional_seguranca.pdf

9. Manthey M. A brief compendium of curious and peculiar aspects of nursing resource management. Creative Nurs. 2018;24(4):231-5 doi: 10.1891/1078-4535.24.4.231

10. Régis TKO, Gohr CF, Santos LC. Implementação do learn healthcare: experiências e lições aprendidas em hospitais brasileiros. Rev Adm Empres. 2018;58(1):30-43. doi: 10.1590/s0034-759020180104 